\title{
Alleviation of the drug-resistant phenotype in idarubicin and cytosine arabinoside double-resistant acute myeloid leukemia cells by indomethacin
}

\author{
JU HAN SONG ${ }^{1,2}$, SEUNG HYUN KIM ${ }^{1,2}$, HYEOUNG-JOON KIM ${ }^{2}$, \\ SEUNG YONG HWANG ${ }^{3}$ and TAE SUNG KIM ${ }^{1,2}$ \\ ${ }^{1}$ School of Life Sciences and Biotechnology, Korea University, Seoul; ${ }^{2}$ Genome Research Center \\ for Hematopoietic Diseases, Chonnam National University Hwasun Hospital, Hwasun; \\ ${ }^{3}$ Division of Molecular and Life Sciences, Hanyang University, Ansan, Republic of Korea
}

Received November 19, 2007; Accepted January 14, 2008

\begin{abstract}
Chemoresistance to anticancer drugs is a major issue in the successful treatment of acute myeloid leukemia (AML). In this study, we developed an AML cell line (AML-2/IDAC) that is resistant to treatment with a combination of idarubicin and cytosine arabinoside (Id/AraC) by chronic exposure for more than 3 months. We then investigated the ability of indomethacin to alleviate the chemoresistance of AML-2/IDAC cells. Treatment with indomethacin alone induced growth arrest, but not the death of AML-2/IDAC cells. However, when AML-2/IDAC cells were treated with combinations of indomethacin and $\mathrm{Id} / \mathrm{AraC}$, the cell death and apoptosis rate of AML-2/IDAC cells were significantly increased in a dose- and time-dependent manner. The combined treatment with indomethacin and $\mathrm{Id} / \mathrm{AraC}$ caused the collapse of the mitochondrial membrane potential and was also demonstrated to enhance the activities of caspase- 3 and -8 in AML-2/IDAC cells. Furthermore, indomethacin down-regulated expression of the ABCA3 and MRP1 genes, which were over-expressed in AML-2/IDAC cells. Taken together, the results of this study suggest that indomethacin can be used to increase the therapeutic potential against drug-resistant AML when combined with anti-leukemic drugs.
\end{abstract}

\section{Introduction}

Chemotherapy has been extensively used for the treatment of patients with acute myeloid leukemia (AML), and one of the recent treatment strategies is based on a combination

Correspondence to: Dr Tae Sung Kim, School of Life Sciences and Biotechnology, Korea University, 5-ga, Anam-dong, Seongbuk-gu, Seoul 136-713, Korea

E-mail: tskim@korea.ac.kr

Key words: ABC-transporter, apoptosis, drug-resistance, indomethacin, acute myeloid leukemia with cytosine arabinoside and anthracyclines (1). Despite the initial success of induction chemotherapy in AML, the remission is often maintained only for a short period of time, and most patients frequently fail to respond consistently to chemotherapy and eventually undergo a relapse $(2,3)$. Because of this unfavorable prognosis, chemoresistance to anticancer drugs is a major issue in the successful treatment of AML.

Several mechanisms of chemoresistance have been identified in hematologic malignancies. One common mechanism is the over-expression of ATP-binding cassette (ABC) transporters (4), through which almost all anti-cancer drugs can be pumped out from cancer cells (5). Several studies have demonstrated that the drug resistance gene (MDR1/P-gp/ $\mathrm{ABCB} 1$ ), multi-drug resistance-associated protein 1 (MRP1/ $\mathrm{ABCC} 1$ ), breast cancer resistance protein (BCRP/ABCG2), and MRP3 (ABCC3) are associated with a poor response of AML cells to anticancer drugs (6-9). In addition, a recent study showed that ABCA3 was strongly correlated with poor prognostics of pediatric AML and that its downregulation with siRNA sensitizes the cells to doxorubicin (10).

Another mechanism of chemoresistance is a defect of the apoptosis pathway, which is triggered by anticancer drugs (11). The activation of initiator and effector caspases by apoptotic stimuli, such as chemotherapeutic drugs, is critical in the process that leads to tumor cell death (12). However, many studies have reported that AML cells with drugresistance can escape from the death process (13-15).

Indomethacin, a non-steroidal anti-inflammatory drug (NSAID), is a well known inhibitor of cyclooxygenases. Recently, many studies have focused on its novel anti-tumor activities $(16,17)$. In this study, we developed an AML cell line (AML-2/IDAC) that was resistant to treatment with a combination of idarubicin and cytosine arabinoside by subjecting the cells to chronic exposure to these compounds for $>3$ months. We then evaluated the antitumor effect of indomethacin on alleviating the chemoresistance of AML-2/ IDAC cells. The results of this study indicate that indomethacin enhances the anticancer drug-induced apoptosis of drug-resistant AML-2/IDAC cells. 


\section{Materials and methods}

Cell lines. The human leukemia AML-2/WT cell line was obtained from the Ontario Cancer Institute (Toronto, Canada) and maintained at $37^{\circ} \mathrm{C}$ in a humidified $5 \% \mathrm{CO}_{2}$ atmosphere in minimum essential medium alpha (MEM $\alpha)$ medium (Gibco BRL, Grand island, NY) supplemented with $10 \%$ heatinactivated fetal bovine serum (HyClone, Logan, UT) and antibiotics (100 U/ml penicillin and $100 \mu \mathrm{g} / \mathrm{ml}$ streptomycin, Gibco BRL). AML-2/IDAC cells were generated from the parental drug-sensitive AML-2/WT cells by chronic co-treatment with idarubicin (Sigma, St. Louis, MO) and cytosine arabinoside (Sigma) for $>3$ months, which led to crossresistance to both drugs.

Cytotoxicity and cell death assays. Exponentially growing cells were seeded into a 96-well culture plate at a density of $2 \times 10^{4}$ cells/well and then cultured in the absence or presence of test drugs for various time periods at $37^{\circ} \mathrm{C}$. After treatment, the cell death induced by the drugs was accessed by a trypan blue exclusion assay. Trypan blue (Sigma) solution $(0.4 \%)$ was then added to each well, and the blue-colored dead cells were counted using a hemacytometer under a light microscope.

Apoptosis detection. DNA fragmentation was used to evaluate the cell apoptosis. To accomplish this, the cells were plated on $100-\mathrm{mm}$ culture dishes and then incubated in the absence or presence of test drugs, such as idarubicin, cytosine arabinoside and indomethacin (Sigma). After treatment, the cells were washed twice with PBS and then incubated for $30 \mathrm{~min}$ with lysis buffer ( $5 \mathrm{mM}$ Tris-Cl, $20 \mathrm{mM}$ EDTA and $0.5 \%$ Triton $\mathrm{X}-100$ ) on ice, followed by centrifugation at 13,500 rpm for $20 \mathrm{~min}$. The supernatants were then incubated for $1 \mathrm{~h}$ with $100 \mu \mathrm{g} / \mathrm{ml} \mathrm{RNase} \mathrm{A}$ (Sigma) at $37^{\circ} \mathrm{C}$, followed by an additional incubation with $100 \mu \mathrm{g} / \mathrm{ml}$ proteinase $\mathrm{K}$ for $1 \mathrm{~h}$. The DNAs were then extracted with phenol/chloroform/isoamyl alcohol (25:24:1) and precipitated with 0.1 volume of $3 \mathrm{M}$ sodium acetate and 0.7 volume of isopropyl alcohol at $-20^{\circ} \mathrm{C}$ overnight. Next, the DNA pellets were resuspended in TE buffer and $5 \mu \mathrm{g}$ of DNA from each sample was then separated on a $2.0 \%$ agarose gel and visualized by ethidium bromide staining. Apoptotic cell death was also assessed by flow cytometric analysis (FACSCalibur, BD, San Diego, CA) of propidium iodide-stained nuclei, as previously described (18). The population of cells that were in specific sub-G1 phase was analyzed by a ModiFit program and these cells were regarded as cells undergoing apoptosis.

Mitochondrial membrane potential $(\Delta \Psi \mathrm{m})$. The collapse in $\Delta \Psi \mathrm{m}$ was measured in cells that were stained with 3,3'dihexyloxacarbocyanine iodide $\left(\mathrm{DiOC}_{6}\right.$, Aldrich Chemical, Milwaukee, WI) solution, as described previously (19). Briefly, AML-2/IDAC cells were cultured in the absence or presence of indomethacin alone or in combination with antileukemic drugs for $48 \mathrm{~h}$. After the treatment, the cells were washed with PBS and incubated for $15 \mathrm{~min}$ in $1 \mathrm{ml}$ PBS containing $100 \mathrm{nM} \mathrm{DiOC}_{6}$ at $37^{\circ} \mathrm{C}$. The cells were then resuspended in PBS, and their $\Delta \Psi \mathrm{m}$ was determined using a flow cytometer.
Reverse transcription-polymerase chain reaction ( $R T-P C R)$. Total RNA from each cell culture was extracted, and cDNA was synthesized as described previously (18). PCR amplification was then conducted using the following primer sets: MRP1 (sense, 5'-ACT CAT TCA GCT CGT CTT GT-3'; antisense, 5'-GAT CCT TGG AGG AGT ACA CA-3'), ABCA3 (sense, 5'-ACC TCC TGA GTC CCG TCA AC-3'; antisense, 5'-CAT ACC CGC TGA TGT ATG CC-3'), MDR1 (sense, 5'-TTT TGG GTG TTA TTT GCT TT-3'; antisense, 5'-GCA TGC TTA AGT TCT TGC TT-3') and $ß$-actin (sense, 5'-AGC GGG AAA TCG TGC GTG-3'; antisense, 5'-CAG GGT ACA TGG TGG TGC C-3'). All PCR products were electrophoresed on a $1.5 \%$ agarose gel, and then visualized under a UV-transilluminator after ethidium bromide staining. The relative band densities were then determined by densitometric analysis using an ImageJ software (Wayne Rasband, NIH, USA).

Western blot analysis. The total cell lysates from each cell culture were subjected to Western blot analysis, as described previously (20), using rabbit anti-caspase 3 and anti-PARP antibodies that were obtained from Upstate (Lake Placid, NY), and goat anti-caspase- 8 and anti-GAPDH antibodies that were purchased from Santa Cruz Biotechnology (Santa Cruz, CA).

Colorimetric analysis of caspase activities. The activities of caspase- 3 and -8 were measured by a colorimetric assay kit (Calbiochem, La Jolla, CA), according to the manufacturer's protocol. Briefly, AML-2/IDAC cells were seeded at a density of $1 \times 10^{5}$ cells $/ \mathrm{ml}$ and then cultured in the absence or presence of indomethacin alone or in combination with antileukemic drugs for $48 \mathrm{~h}$. After incubation, the proteins were obtained from the cells using lysis buffer without protease inhibitors, as described above. Each protein sample $(200 \mu \mathrm{g})$ was then mixed with $200 \mu \mathrm{M}$ Ac-DEVD-pNA or Ac-IETD-pNA, respectively. The mixtures were then incubated for $2 \mathrm{~h}$ in $37^{\circ} \mathrm{C}$, and the absorbance at $400 \mathrm{~nm}$ was read using a microplate reader. The data are presented as a fold-change by comparing the result obtained from the treated samples with that of the untreated control sample.

Statistical analysis. The results are expressed as the mean \pm SD of data obtained from three or four independent experiments performed in triplicate. Statistical significance was determined using the Student's t-test.

\section{Results}

Sensitivities of AML-2/WT and AML-2/IDAC cells to anticancer drugs. Idarubicin and cytosine arabinoside (Id/AraC) double-resistant AML-2/IDAC cells were generated from drug-sensitive AML-2/WT cells by chronic exposure to $\mathrm{Id} / \mathrm{AraC}$. To compare the susceptibility of AML-2/WT and AML-2/IDAC cells to Id/AraC, both cell lines were cultured in the absence or presence of various concentrations of Id/AraC. As shown in Fig. 1A, AML-2/IDAC cells were resistant to the cytotoxic response of Id/AraC when compared to the parental AML-2/WT cells. In addition, cellular DNA obtained from AML-2/IDAC cells exhibited no or less laddering to the 
A

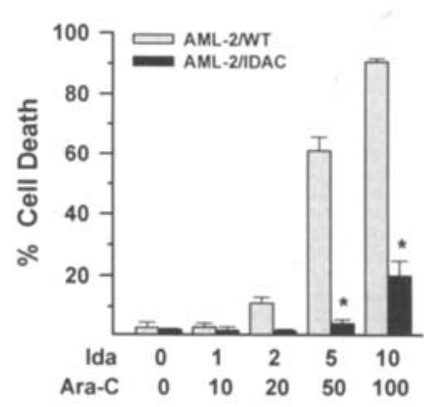

B

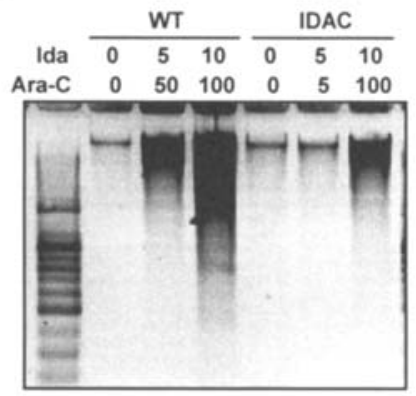

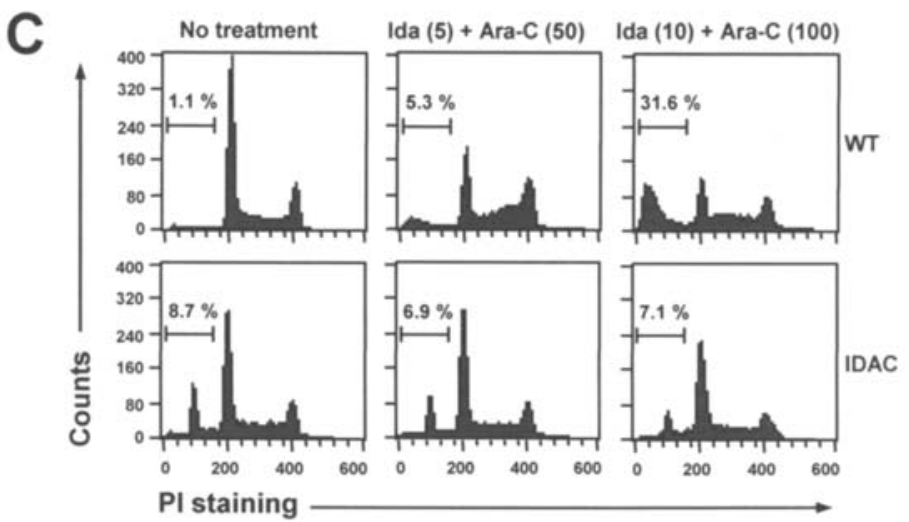

Figure 1. Susceptibility of AML-2/WT and AML-2/IDAC cells to anticancer drugs. (A) AML-2/WT and AML-2/IDAC cells were treated with both idarubicin (Ida, ng/ml) and cytosine arabinoside (Ara-C, ng/ml) for $48 \mathrm{~h}$. Cell death was then evaluated by the trypan blue exclusion assay. Data are expressed as the mean $\pm \mathrm{SD}$ of three independent experiments. ${ }^{*} \mathrm{P}<0.001$, relative to a group of AML-2/WT cells. (B and C) At $24 \mathrm{~h}$ after treatment, the cells were also harvested to access the apoptotic death. Cellular DNA was extracted from the cells and separated on $2.0 \%$ agarose gel (B). Propidium iodide-stained cells were analyzed for DNA content using a flow cytometer (C). All data are representative of three independent experiments.

anticancer drugs rather than the AML-2/WT cells (Fig. 1B). Furthermore, the population of cells in the sub-G1 phase was unchanged in the drug-resistant AML-2/IDAC cells (Fig. 1C). These findings indicate that the AML-2/IDAC cells are highly resistant to the cytotoxic activities of anticancer drugs, Id/AraC.

Increase of anticancer drug-induced death of AML-2/IDAC cells by indomethacin. To alleviate the drug-resistant phenotypes of AML-2/IDAC cells, the cells were treated with a combination of $\mathrm{Id} / \mathrm{AraC}$ and indomethacin, and the cytotoxic levels were determined. As shown in Fig. 2, treatment with either $\mathrm{Id} / \mathrm{AraC}$ or indomethacin resulted in relatively low cytotoxic activity against AML-2/IDAC cells. Interestingly, the combined treatment of $\mathrm{Id} / \mathrm{AraC}$ with indomethacin was demonstrated to effectively induce the death of AML-2/IDAC cells in a dose- and time-dependent manner (Fig. 2).

Enhancing effect of indomethacin on Id/AraC-induced apoptosis of AML-2/IDAC cells. We next examined the effect of indomethacin on anticancer drug-induced apoptosis in AML-2/IDAC cells. As shown in Fig. 3A, the cell cycle analysis revealed that treatment with a combination of Id/ $\mathrm{AraC}$ and indomethacin strongly increased the proportion of the cell population that was in the sub-G1 phase. Additionally, co-treatment of AML-2/IDAC cells with indomethacin and $\mathrm{Id} / \mathrm{AraC}$ resulted in enhanced activation of caspase- 3 and -8 , and also induced cleavage of PARP (Fig. 3B). Colorimetric analysis of the caspase activity also indicated that

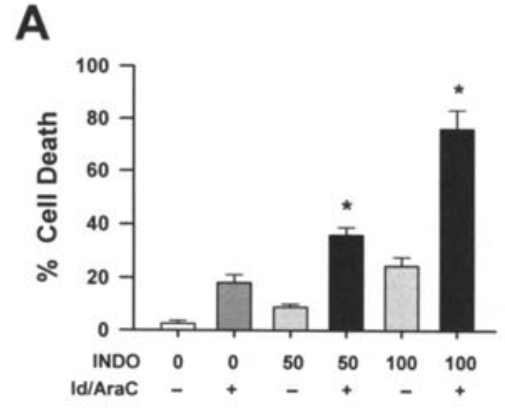

B

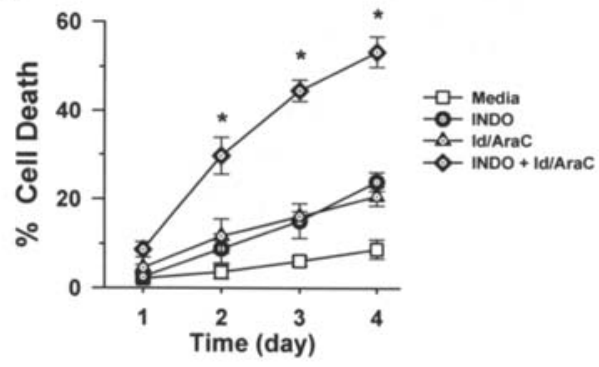

Figure 2. Effects of indomethacin on anticancer drug-induced death of drug-resistant AML-2/IDAC cells. AML-2/IDAC cells were treated with indomethacin (INDO, $\mu \mathrm{g} / \mathrm{ml}$ ) alone or in combination with $10 \mathrm{ng} / \mathrm{ml}$ idarubicin and $100 \mathrm{ng} / \mathrm{ml}$ cytosine arabinoside (Id/AraC). (A) At $48 \mathrm{~h}$ after treatment, cell death in each culture was evaluated by the trypan blue exclusion assay. (B) After each treatment, cell death was also accessed by the same method at various time-points. Data are expressed as the mean \pm SD of four independent experiments. ${ }^{*} \mathrm{P}<0.001$, relative to an untreated group. 

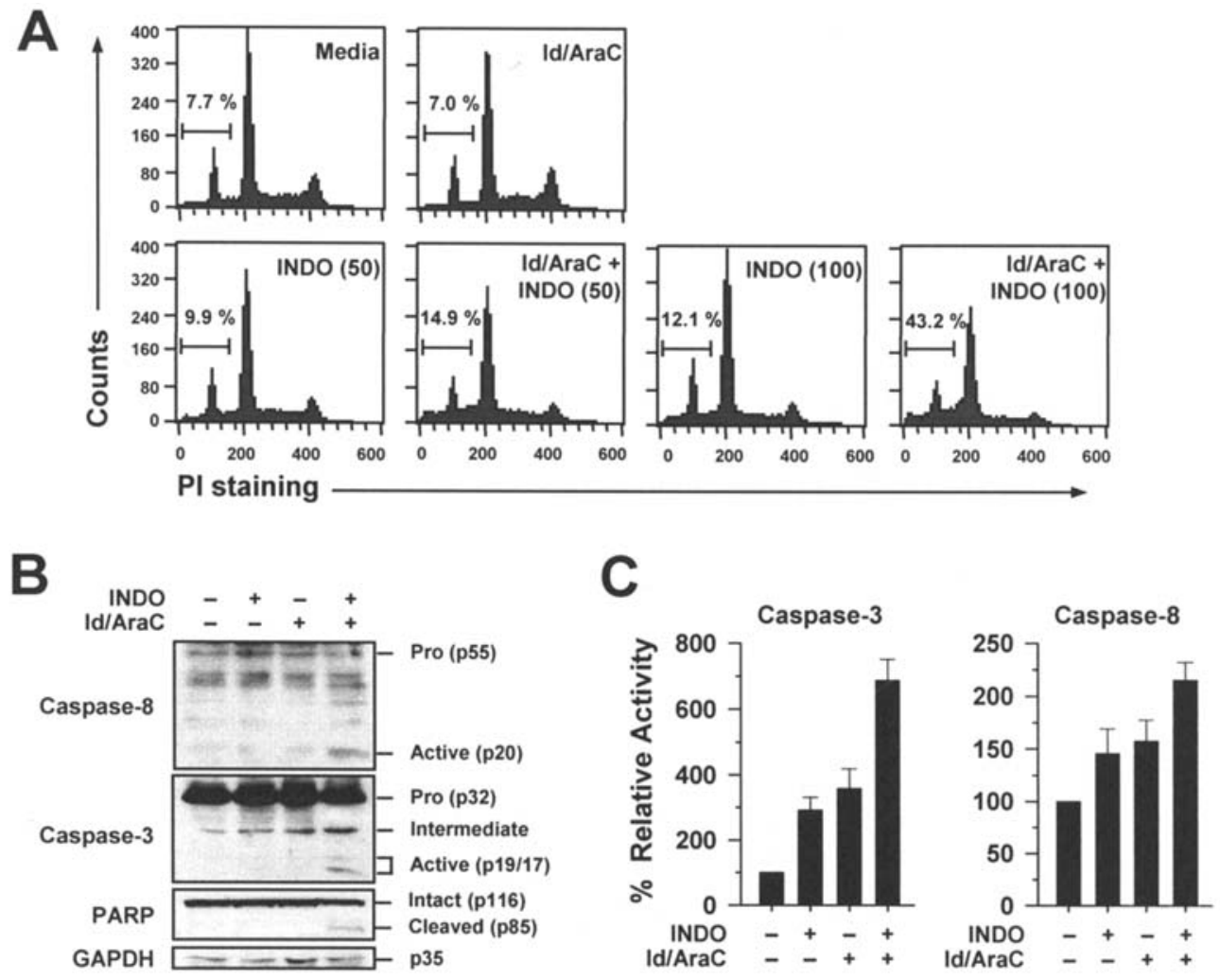

Figure 3. Effects of indomethacin in anticancer drug-induced apoptosis of AML-2/IDAC cells. AML-2/IDAC cells were treated for $48 \mathrm{~h}$ with indomethacin (INDO, $50 \mu \mathrm{g} / \mathrm{ml}$ ) alone or in combination with anticancer drugs (Id/AraC), including $10 \mathrm{ng} / \mathrm{ml}$ idarubicin and $100 \mathrm{ng} / \mathrm{ml}$ cytosine arabinoside. (A) Cell death was determined by flow cytometric analysis with propidium iodide staining. The population of cells in the sub-G1 phase of cell cycle represents apoptotic death of the cells. (B) Total cell lysates were separated on SDS-PAGE gel. Western blotting was performed using specific antibodies for each protein. GAPDH was used as an internal loading control. (C) Activities of caspase-3 and -8 under each condition were accessed by colorimetric analysis using their specific substrates. Data are expressed as the mean \pm SD of three independent experiments.

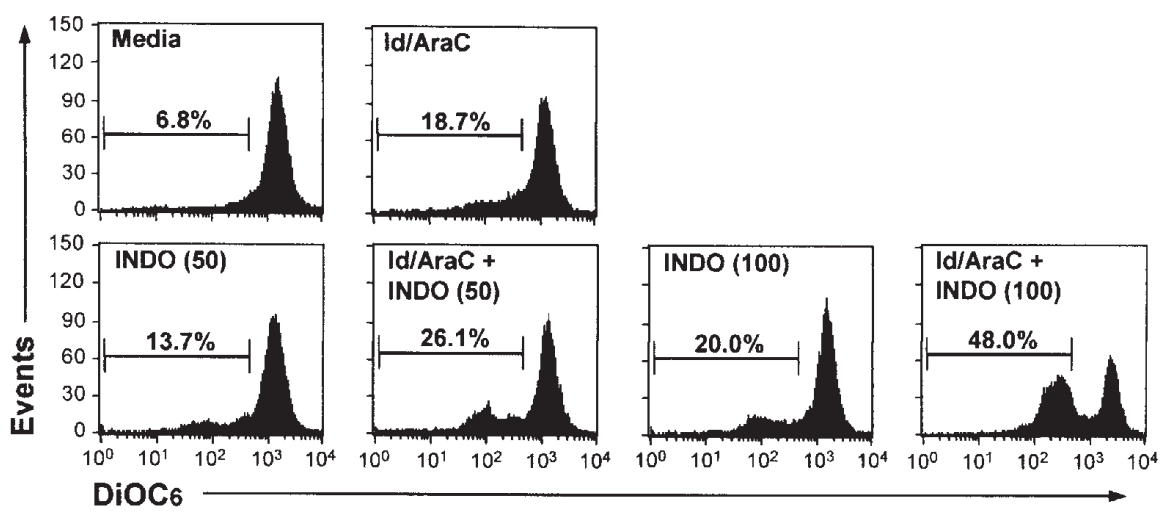

Figure 4. Changes of mitochondrial membrane potential $(\Delta \Psi \mathrm{m})$ in AML-2/IDAC cells by the combined treatment with anticancer drugs and indomethacin. AML-2/IDAC cells were treated with indomethacin (INDO, $\mu \mathrm{g} / \mathrm{ml}$ ) alone or in combination with anticancer drugs (Id/AraC), including $10 \mathrm{ng} / \mathrm{ml}$ idarubicin and $100 \mathrm{ng} / \mathrm{ml}$ cytosine arabinoside. At $48 \mathrm{~h}$ after treatment, the cells were harvested and washed with PBS, followed by a staining with DiOC 6 solution, and the changes in their $\Delta \Psi \mathrm{m}$ were then evaluated by flow cytometric analysis.

indomethacin co-operated with $\mathrm{Id} / \mathrm{AraC}$ to activate caspase-3 and -8 in AML-2/IDAC cells (Fig. 3C).

Previous studies have shown that anticancer drugs induced intrinsic apoptosis via dysfunction of the mitochondrial pathway as well as extrinsic apoptosis by caspases (21). Therefore, to determine if the apoptotic death induced by the combination of indomethacin and $\mathrm{Id} / \mathrm{AraC}$ was associated with the mitochondrial pathway, the $\Delta \Psi \mathrm{m}$ changes were evaluated in
AML-2/IDAC cells. As shown in Fig. 4, combination treatment with indomethacin and $\mathrm{Id} / \mathrm{AraC}$ strongly promoted the collapse of $\Delta \Psi \mathrm{m}$ in AML-2/IDAC cells when compared with that of samples treated with either indomethacin or Id/AraC (Fig. 4).

Altered expressions of ABC-transporters in AML-2/IDAC cells and their modulation by indomethacin. To determine whether 
A

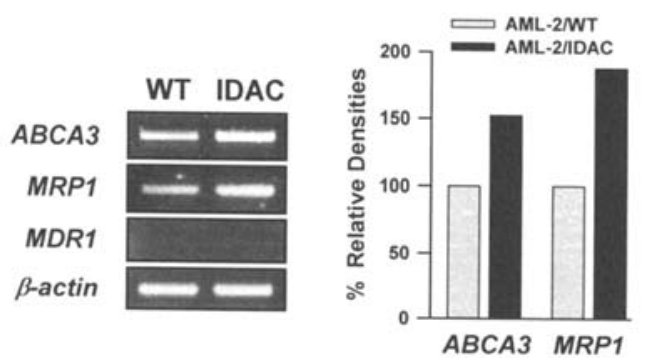

B
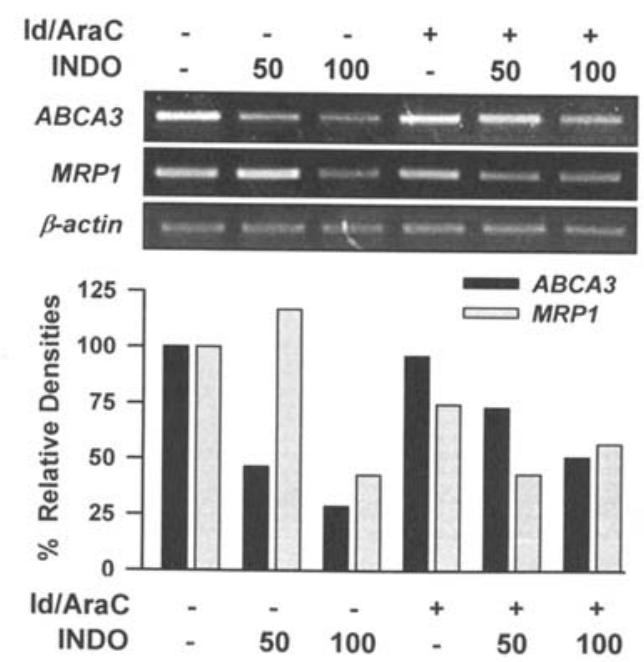

Figure 5. Altered gene expression of ABC-transporters in AML-2/IDAC cells and their modulation by indomethacin. (A) AML-2/WT (WT) and AML-2/IDAC (IDAC) cells were incubated under normal conditions for $24 \mathrm{~h}$. RT-PCR analyses of the RNA samples obtained from both cells were then performed, and the products were separated on a $1.5 \%$ agarose gel and visualized by ethidium bromide staining. B-actin was used as an internal control. The relative band densities of ABCA3 and MRP1 to $\beta$-actin were then calculated by densitometric analysis. (B) AML-2/IDAC cells were treated for $24 \mathrm{~h}$ with indomethacin (INDO, $\mu \mathrm{g} / \mathrm{ml}$ ) alone or in combination with anticancer drugs (Id/AraC), including $10 \mathrm{ng} / \mathrm{ml}$ idarubicin and $100 \mathrm{ng} / \mathrm{ml}$ cytosine arabinoside. RT-PCR analyses were then conducted. $B$-actin was used as an internal control. The band densities of ABCA3 and MRP1 relative to $ß$-actin were evaluated by densitometric analysis.

the drug-resistant ability of AML-2/IDAC cells was correlated with over-expression of ABC-transporters, the expression levels of several drug-efflux pumps were determined in both AML-2/WT and AML-2/IDAC cells. As shown in Fig. 5A, ABCA3 and MRP1 genes were over-expressed in AML2/IDAC cells, when compared to the expression levels observed in AML-2/WT cells. However, expression of the MDR1 gene was not detected in either cell line.

We next asked if the enhanced susceptibility of AML-2/ IDAC cells to Id/AraC by indomethacin was due to downregulation of the $\mathrm{ABCA} 3$ and $\mathrm{MRP} 1$ genes, which were elevated in AML-2/IDAC cells. As shown in Fig. 5B, the expression levels of the ABCA3 and MRP1 genes were not changed by treatment with $\mathrm{Id} / \mathrm{AraC}$. Interestingly, treatment with indomethacin alone or in combination with $\mathrm{Id} / \mathrm{AraC}$ inhibited expression of the ABCA3 and MRP1 genes in AML2/IDAC cells (Fig. 5B), which indicates that indomethacin may enhance the Id/AraC-induced cell death of AML-2/IDAC cells by down-modulation of some drug-efflux pumps.

\section{Discussion}

Anticancer drug resistance is a major obstacle in the treatment of leukemia, therefore many trials evaluating leukemia treatment have been conducted (22-24). In this study, combined treatment with indomethacin was shown to potentiate a chemotherapy-induced apoptosis in drug-resistant AML-2/ IDAC cells. Co-treatment with indomethacin was also found to decrease the expression levels of $\mathrm{ABC}$ transporter genes, such as ABCA3 and MRP1, which were over-expressed in AML-2/IDAC cells.

An increasing number of studies have indicated that NSAIDs has antitumor effects. For example, Giardiello et al and Sinicrope et al showed that sulindac can be clinically used for the treatment of colorectal malignancy $(25,26)$. In studies of leukemia, evaluation of the anti-leukemic activity of NSAIDs has focused on attempts to overcome drug-resistance to chemotherapy (27). A major mechanism responsible for the effectiveness of NSAIDs has been shown to be the suppression of MRP1 but not MDR1 $(27,28)$. Therefore, in the present study, we generated AML-2/IDAC cells that expressed MRP1 but not MDR1 through chronic exposure of drugsensitive AML-2/WT cells to $\mathrm{Id} / \mathrm{AraC}$, which is extensively used in leukemia chemotherapy. Treatment with indomethacin down-regulated the MRP1 expression in AML-2/IDAC cells. Interestingly, drug-resistant AML-2/IDAC cells exhibited higher expression of $\mathrm{ABCA} 3$ than their parental cells. Although its involvement in drug-resistance has not been fully demonstrated, recent studies have suggested that ABCA3 is strongly correlated in the drug-response of AML cells $(10,29,30)$. Here, we demonstrate for the first time that indomethacin can modulate expression of the ABCA3 gene, which suggests that $\mathrm{ABCA} 3$ is a new therapeutic target of indomethacin in cancer chemotherapy.

Another mechanism by which antileukemic activity of NSAIDs occurs is via induction of the activation of caspases, which leads to apoptosis in leukemia cells $(16,31)$. Using our cell line models, we compared the apoptotic response to chemotherapeutic drugs in both drug-sensitive and -resistant leukemia cells. We observed a defect in drug-induced apoptosis in AML-2/IDAC cells. This phenotype was recovered by the combined treatment with indomethacin and anticancer drugs. In addition to the activation of caspase- 3 and -8 , the collapse of $\Delta \Psi \mathrm{m}$ suggested that the enhanced cell death induced by indomethacin was associated with an intrinsic apoptosis pathway (21).

Taken together, the results of this study indicate that indomethacin can alleviate the drug-resistant phenotype in AML cells, and that this occurs by activation of a chemotherapeutic drug-induced apoptotic pathway and suppression of some $\mathrm{ABC}$ transporters, such as $\mathrm{ABCA} 3$ and MRP1. In spite of the beneficial effect of indomethacin in the treatment of drug-resistant leukemia, further study is necessary to evaluate its clinical relevance.

\section{Acknowledgements}

This work was supported by a grant of the Korea Health 21 R\&D Project, Ministry of Health \& Wealfare, Republic of Korea (01-PJ10-PG6-01GN16-0005). 


\section{References}

1. Tallman MS, Gilliland DG and Rowe JM: Drug therapy for acute myeloid leukemia. Blood 106: 1154-1163, 2005

2. Newland A: Progress in the treatment of acute myeloid leukaemia in adults. Int J Hematol 76: 253-258, 2002

3. Styczynski J: Drug resistance in childhood acute myeloid leukemia. Curr Pharm Biotechnol 8: 59-75, 2007.

4. Van der Kolk DM, De Vries EG, Müller M and Vellenga E: The role of drug efflux pumps in acute myeloid leukemia. Leuk Lymphoma 43: 685-701, 2002.

5. Choi $\mathrm{CH}$ : $\mathrm{ABC}$ transporters as multidrug resistance mechanisms and the development of chemosensitizers for their reversal. Cancer Cell Int 5: 30, 2005.

6. Tidefelt U, Liliemark J, Gruber A, Liliemark E, SundmanEngberg B, Juliusson G, Stenke L, et al: P-Glycoprotein inhibitor valspodar (PSC 833) increases the intracellular concentrations of daunorubicin in vivo in patients with $\mathrm{P}$ glycoprotein-positive acute myeloid leukemia. J Clin Oncol 18: 1837-1844, 2000

7. Schneider E, Cowan KH, Bader H, Toomey S, Schwartz GN, Karp JE, Burke PJ, et al: Increased expression of the multidrug resistance-associated protein gene in relapsed acute leukemia. Blood 85: 186-193, 1995.

8. Steinbach D, Sell W, Voigt A, Hermann J, Zintl F and Sauerbrey A: BCRP gene expression is associated with a poor response to remission induction therapy in childhood acute myeloid leukemia. Leukemia 16: 1443-1447, 2002.

9. Steinbach D, Lengemann J, Voigt A, Hermann J, Zintl F and Sauerbrey A: Response to chemotherapy and expression of the genes encoding the multidrug resistance-associated proteins MRP2, MRP3, MRP4, MRP5, and SMRP in childhood acute myeloid leukemia. Clin Cancer Res 9: 1083-1086, 2003.

10. Steinbach D, Gillet JP, Sauerbrey A, Gruhn B, Dawczynski K Bertholet V, De Longueville F, et al: ABCA3 as a possible cause of drug resistance in childhood acute myeloid leukemia. Clin Cancer Res 12: 4357-4363, 2006.

11. Tourneur L, Delluc S, Lévy V, Valensi F, Radford-Weiss I, Legrand O, Vargaftig J, et al: Absence or low expression of fasassociated protein with death domain in acute myeloid leukemia cells predicts resistance to chemotherapy and poor outcome. Cancer Res 64: 8101-8108, 2004

12. Hengartner MO: The biochemistry of apoptosis. Nature 407: 770-776, 2000

13. Smith BD, Bambach BJ, Vala MS, Barber JP, Enger C, Brodsky RA, Burke PJ, et al: Inhibited apoptosis and drug resistance in acute myeloid leukaemia. Br J Haematol 102: 1042-1049, 1998.

14. Olsson A, Norberg M, Okvist A, Derkow K, Choudhury A, Tobin $\mathrm{G}$, Celsing F, et al: Upregulation of bfl-1 is a potential mechanism of chemoresistance in B-cell chronic lymphocytic leukaemia. Br J Cancer 97: 769-777, 2007

15. Inaba H, Shimada K, Zhou YW, Ido M, Buck S, Yonehara S Kaplan J, et al: Acquisition of Fas resistance by Fas receptor mutation in a childhood B-precursor acute lymphoblastic leukemia cell line, MML-1. Int J Oncol 27: 573-579, 2005.

16. Zhang G, Tu C, Zhang G, Zhou G and Zheng W: Indomethacin induces apoptosis and inhibits proliferation in chronic myeloid leukemia cells. Leuk Res 24: 385-392, 2000.

17. Liou JY, Ghelani D, Yeh S and Wu KK: Non-steroidal antiinflammatory drugs induce colorectal cancer cell apoptosis by suppressing 14-3-3epsilon. Cancer Res 67: 3185-3191, 2007.
18. Song JH, Choi CH, Yeom HJ, Hwang SY and Kim TS Monitoring the gene expression profiles of doxorubicin-resistant acute myelocytic leukemia cells by DNA microarray analysis. Life Sci 79: 193-202, 2006

19. Lee DH, Park T and Kim HW: Induction of apoptosis by disturbing mitochondrial-membrane potential and cleaving PARP in Jurkat T cells through treatment with acetoxyscirpenol mycotoxins. Biol Pharm Bull 29: 648-654, 2006.

20. Park J, Kim SH, Cho D and Kim TS: Formononetin, a phytooestrogen, and its metabolites up-regulate interleukin-4 production in activated $\mathrm{T}$ cells via increased AP-1 DNA binding activity. Immunology 116: 71-81, 2005

21. Rojewski MT, Körper S, Thiel E and Schrezenmeier H: Depolarization of mitochondria and activation of caspases are common features of arsenic(III)-induced apoptosis in myelogenic and lymphatic cell lines. Chem Res Toxicol 17: 119-128, 2004 .

22. Kishimoto Y, Sampi K, Kuraishi Y, Takemoto Y, Okabe K, Tamura K, Mizoguchi H, et al: A phase II study employing combination regimens containing KRN8602 in drug-resistant acute myeloid leukemia and acute lymphoblastic leukemia. KRN8602 Leukemia Study Group. Anticancer Drugs 10: 267-273, 1999.

23. Tang R, Faussat AM, Majdak P, Perrot JY, Chaoui D, Legrand O and Marie JP: Valproic acid inhibits proliferation and induces apoptosis in acute myeloid leukemia cells expressing P-gp and MRP1. Leukemia 18: 1246-1251, 2004

24. Van der Holt B, Löwenberg B, Burnett AK, Knauf WU, Shepherd J, Piccaluga PP, Ossenkoppele GJ, et al: The value of the MDR1 reversal agent PSC-833 in addition to daunorubicin and cytarabine in the treatment of elderly patients with previously untreated acute myeloid leukemia (AML), in relation to MDR1 status at diagnosis. Blood 106: 2646-2654, 2005.

25. Giardiello FM, Hamilton SR, Krush AJ, Piantadosi S, Hylind LM, Celano P, Booker SV, et al: Treatment of colonic and rectal adenomas with sulindac in familial adenomatous polyposis. $\mathrm{N}$ Engl J Med 328: 1313-1316, 1993

26. Sinicrope FA, Pazdur R and Levin B: Phase I trial of sulindac plus 5-fluorouracil and levamisole: potential adjuvant therapy for colon carcinoma. Clin Cancer Res 2: 37-41, 1996.

27. Duffy CP, Elliott CJ, O'Connor RA, Heenan MM, Coyle S, Cleary IM, Kavanagh K, et al: Enhancement of chemotherapeutic drug toxicity to human tumour cells in vitro by a subset of non-steroidal anti-inflammatory drugs (NSAIDs). Eur J Cancer 34: 1250-1259, 1998.

28. Matsunaga S, Asano T, Tsutsuda-Asano A and Fukunaga Y: Indomethacin overcomes doxorubicin resistance with inhibiting multi-drug resistance protein 1 (MRP1). Cancer Chemother Pharmacol 58: 348-353, 2006.

29. Norwood K, Wang RY, Hirschmann-Jax C, Andreeff M, Brenner MK, Goodell MA and Wulf GG: An in vivo propagated human acute myeloid leukemia expressing ABCA3. Leuk Res 28: 295-299, 2004.

30. Wulf GG, Modlich S, Inagaki N, Reinhardt D, Schroers R, Griesinger F and Trümper L: ABC transporter ABCA3 is expressed in acute myeloid leukemia blast cells and participates in vesicular transport. Haematologica 89: 1395-1397, 2004.

31. Bellosillo B, Piqué M, Barragán M, Castaño E, Villamor N, Colomer D, Montserrat E, et al: Aspirin and salicylate induce apoptosis and activation of caspases in B-cell chronic lymphocytic leukemia cells. Blood 92: 1406-1414, 1998. 